\section{Dinâmica voltada para jovens escolares visando a compreensão da importância dos macronutrientes para a homeostasia celular}

\author{
Dynamics focused at young school people aiming \\ at understanding the importance of \\ macronutrients for cellular homeostasis
}

\section{Flávia Yumi Sinzato ${ }^{1}$, Fernando Rodrigues Cordeiro ${ }^{2}$, Ana Clara Dal Bosco ${ }^{3}$, Isabella de Freitas Starling Barcellos Gonçalves ${ }^{4}$, Ludimila Canuto Faccioni ${ }^{5}$}

\author{
RESUMO
}

\begin{abstract}
A educação é o melhor instrumento para promover a reflexão sobre a saúde e a doença. Sendo assim, as estratégias didáticas podem colaborar com o processo de aprendizado e conscientização sobre os benefícios e malefícios dos alimentos. Sabendo-se que 50\% dos jovens do Mato Grosso do Sul consomem regularmente alimentos industrializados e apresentam alto índice de diabetes, foi desenvolvida a ação de extensão do presente relato. A proposta foi baseada no trabalho por meio de ludicidade e dinâmicas, da conscientização de jovens sobre o que consomem diariamente e a importância dos nutrientes para a sua homeostasia celular. A ação foi voltada para alunos do ensino médio de escola pública de Campo Grande -MS, enquanto estes participavam do projeto de extensão "A célula e a Origem da Doença: Um tema médico desafiador para o Ensino Médio- 2a edição". As atividades foram desenvolvidas por graduandos do primeiro ano do curso de Medicina. Na estação de ensino denominada "Cozinha e Saúde", os participantes puderam vivenciar uma sequência de atividades lúdicas e dinâmicas para aquisição de conhecimentos, sobre os macronutrientes e sua importância para a célula, o volume de açúcar em nossos alimentos e a relevância da interpretação de rótulos alimentícios. Das atividades propostas, a que mais impactou os adolescentes foi a descoberta sobre a quantidade de açúcar presente nos alimentos e o quanto isso pode afetar as células levando ao desenvolvimento de doenças. Essa ação tornou palavras e números mais concretos e motivou a conscientização dos jovens participantes sobre a importância de uma alimentação saudável.
\end{abstract}

Palavras-chave: Açúcar. Extensão Universitária. Célula. Rótulo. Hábitos Alimentares.

\footnotetext{
${ }^{1}$ Graduação. Universidade Federal de Mato Grosso do Sul (UFMS), Campo Grande, Mato Grosso do Sul, Brasil. E-mail: yumi_sinzato@ufms.br. Orcid: https://orcid.org/0000-0001-5576-1155

${ }^{2}$ Graduação. Universidade Federal de Mato Grosso do Sul (UFMS), Campo Grande, Mato Grosso do Sul, Brasil. E-mail: fernando.cordeiro@ufms.br . Orcid: https://orcid.org/0000-0002-8591-2273

${ }^{3}$ Graduação. Universidade Federal de Mato Grosso do Sul (UFMS), Campo Grande, Mato Grosso do Sul, Brasil. E-mail: anaclaradalboscosena@gmail.com. Orcid: https://orcid.org/0000-0002-4955-3269

${ }^{4}$ Graduação. Universidade Federal de Mato Grosso do Sul (UFMS), Campo Grande, Mato Grosso do Sul, Brasil. E-mail: isa.starlingg @ gmail.com. Orcid: https://orcid.org/0000-0001-6358-0346

${ }_{5}^{5}$ Doutorado. Universidade Federal de Mato Grosso do Sul (UFMS), Campo Grande, Mato Grosso do Sul, Brasil. E-mail: ludimila.faccioni@ufms.br. Orcid: https://orcid.org/0000-0001-6145-2236
} 


\begin{abstract}
Education is the best tool to promote reflection on health and disease. Therefore, didactic strategies can contribute to the process of learning and awareness of the benefits and harms of food. Based on previous information that $50 \%$ of young people from Mato Grosso do Sul State regularly consume processed foods and have high diabetes rates, the approach on the food habits is necessary. The extension project was developed by considering working through playfulness and dynamics, the awareness of young people about what they consume daily and the importance of nutrients for their cellular homeostasis. The target of this project were public high school students in Campo Grande - MS, while they participated in the extension project "The cell and the origin of the disease: a challenging medical theme for high school - 2nd edition". The activities were developed by first-year undergraduates of the Medicine course. In the teaching station called "Kitchen and Health", the participants were submitted to a sequence of playful and dynamic activities to acquire knowledge mainly about macronutrients and their importance for the body cells, the volume of sugar in our usual food and the relevance of food label's reading. Taking in account all proposed activities, the one that most impacted adolescents was the discovery about amount of sugar in food and how much this can affect the development of diseases. This action made words and numbers more concrete and motivated the awareness of young participants about the importance of healthy eating.
\end{abstract}

Keywords: Sugar. University Extension. Cell. Label. Food habits.

\title{
INTRODUÇÃO
}

O Projeto de Extensão "A Célula e a Origem da Doença: Um tema médico desafiador para o Ensino Médio" (FACCIONI; SOLER, 2018), criado no final de 2015, abordou de forma integrada em sua segunda edição a importância dos micro e macronutrientes para a composição estrutural e funcional celular e como o desequilíbrio na disponibilidade desses componentes pode facilitar o desenvolvimento de doenças crônicas como a obesidade e o diabetes.

No Estado do Mato Grosso do Sul a abordagem dessa temática para a população jovem é relevante, uma vez que $50 \%$ do jovens sul mato-grossenses consomem regularmente alimentos industrializados e embutidos (BRASIL, 2018), os quais são ricos, principalmente, em sódio e açúcar (ANVISA, 2010). Segundo um estudo liderado pelo Imperial College London e pela Organização Mundial da Saúde (OMS), o número de crianças e adolescentes obesos em todo o mundo aumentou dez vezes nos últimos 40 anos (OPAS, 2017). Tal condição explicaria, em grande parte, o avanço do diabetes mellitus 
tipo II (DM2) nesse grupo, assim como o desenvolvimento da síndrome metabólica, aliada a doenças cardiovasculares na vida adulta (SBD, 2014-2015a).

A educação é o melhor instrumento para promover a reflexão sobre a saúde e a doença; e estratégias didáticas podem colaborar com o processo de aprendizado. No ensino, estratégias diversas têm maior sucesso do que a mera explicação teórica, pois torna a dinâmica do aprendizado mais descontraída, permitindo o desenvolvimento da criatividade e da motivação pelo saber (KLAUBERG, 2015). Segundo a Base Nacional Comum Curricular (BRASIL, 1996), a promoção de uma abordagem investigativa pelo educador facilita o progresso cognitivo do aluno e o estimula a ser o protagonista do próprio aprendizado (AMORIM, 2013). Aliar a abordagem investigativa a elementos lúdicos e dinâmicos podem levar a retenção de até $75 \%$ das informações trabalhadas com os estudantes, segundo Oblinger (1993). Nessa perspectiva, diversas ferramentas devem ser consideradas para que o aluno escolha, entre muitos caminhos, o que mais se aproxima aos seus valores e à sua visão de mundo (ARAUJO, 2012), para que essa informação seja significativa em sua vida. Para a eficiente apropriação do conhecimento, na dependência da forma como ela seja conduzida, a utilização de modelos didáticos pode facilitar a assimilação de mecanismos porque envolvem a memória visual e a materialização das estruturas pelo indivíduo que recebe a informação (ORLANDO et al., 2009; AMORIM, 2013).

Na educação nutricional, nota-se uma significativa carência de conhecimento dos jovens sobre o alimento que consomem, situação agravada pela influência da mídia e dos profissionais de saúde, os quais não raramente desconhecem outras formas de abordarem essa temática e acabam por propagarem as mesmas informações e noções de um comer certo e um comer errado (RODRIGUES et al., 2006). Tal dicotomização impede que os adolescentes, e também seus familiares busquem o equilíbrio, uma vez que o comer certo pressupõe a exclusão de todos os alimentos que compõem o grupo dos maus e é percebido como restrição e anulação de todos os prazeres, tanto alimentares quanto sociais. Dessa forma, problematizar o aparecimento de doenças potencialmente evitadas, como obesidade e diabetes tipo 2, consiste na ruptura desse padrão dicotômico de pensamento, de forma que os adolescentes passem a perceber que não existem apenas essas duas formas de se alimentarem (RODRIGUES et al., 2006). 
O presente trabalho objetiva, por meio de uma estação de atividade de ensino, cientificar escolares do ensino médio sobre a quantidade de micro e macronutrientes nos alimentos que ingerem diariamente e sua importância para a célula, além de promover uma reflexão para mudanças de hábitos alimentares.

\section{RELATO DE EXPERIÊNCIA}

A estação de ensino proposta a estudantes da Escola Estadual Orcírio Thiago de Oliveira foi desenvolvida por acadêmicos do Curso de Medicina e teve como sede a Casa da Ciência da Universidade Federal do Mato Grosso, Campo Grande - MS. Nesse processo, os estudantes de medicina durante cinco meses anteriores ao dia da ação, se reuniram semanalmente para estudar sobre os macronutrientes, sobre a importância desses elementos para a célula e sobre a relevância da interpretação de rótulos alimentícios, visando a prevenção de doenças como diabetes e obesidade. Como resultado dos encontros, foram construídos modelos e sequências didáticas para compor as atividades da estação de ensino, a qual denominaram de Estação Cozinha e Saúde. As atividades da estação foram desenvolvidas para ser trabalhada com 6 a 8 estudantes, com duração de 25 minutos.

Sequência didática das atividades propostas pela estação de ensino:

Atividade 1 - Após boas-vindas e apresentação da equipe aos escolares, os acadêmicos sugeriram aos alunos responderem voluntariamente a um breve questionário (Quadro 1) sobre o hábito alimentar. Não era necessário a identificação do aluno. O objetivo desse questionário não era resultar em pesquisa científica, mas sim estimular o estudante a observar os seus próprios hábitos para reflexão em atividades seguintes (THIOLLENT, 1994). Foi permitido assinalar mais de uma alternativa para a mesma pergunta.

Quadro 1. Questionário elaborado para promover reflexão entres os alunos.

\begin{tabular}{|l|l|l|l|l|}
\hline Perguntas & \multicolumn{4}{l|}{ Respostas } \\
\hline $\begin{array}{l}\text { Quantas frutas você } \\
\text { come por dia? }\end{array}$ & $0(\quad)$ & $1(\quad)$ & $2(\quad)$ & 3 ou mais ( ) \\
\hline
\end{tabular}




\begin{tabular}{|c|c|c|c|c|}
\hline $\begin{array}{l}\text { O equivalente a quantos } \\
\text { saches de sal }(1 \mathrm{~g}) \text { você } \\
\text { ingere por dia? }\end{array}$ & 1 a $5(\quad)$ & 5 a $10(\quad)$ & Mais de 10() & \\
\hline $\begin{array}{l}\text { Com que frequência você } \\
\text { toma refrigerante? }\end{array}$ & Todos os dias ( ) & $\begin{array}{l}\text { Uma vez por } \\
\text { semana }(\quad)\end{array}$ & $\begin{array}{l}\text { Uma vez por } \\
\text { mês ( ) }\end{array}$ & Nenhuma ( ) \\
\hline $\begin{array}{l}\text { Com que frequência você } \\
\text { como doce (chocolate, } \\
\text { bala, sorvete etc.)? }\end{array}$ & Todos os dias ( ) & $\begin{array}{l}\text { Uma vez por } \\
\text { semana }(\quad)\end{array}$ & $\begin{array}{l}\text { Uma vez por } \\
\text { mês }(\quad)\end{array}$ & $\begin{array}{l}\text { Nenhuma } \\
(\quad)\end{array}$ \\
\hline $\begin{array}{l}\text { Come vegetais e legumes } \\
\text { todos os dias? }\end{array}$ & $\operatorname{Sim}(\quad)$ & Não ( ） & & \\
\hline $\begin{array}{l}\text { Tem costume de olhar o } \\
\text { rótulo dos alimentos? }\end{array}$ & $\operatorname{Sim}(\quad)$ & Não（） & Às vezes ( ） & \\
\hline $\begin{array}{l}\text { Pratica algum esporte ou } \\
\text { frequenta a academia? }\end{array}$ & $\operatorname{Sim}(\quad)$ & Não ( ） & Às vezes ( ） & Gostaria ( ) \\
\hline $\begin{array}{l}\text { Em um lanche, você } \\
\text { escolheria o quê? }\end{array}$ & $\begin{array}{l}\text { Salgadinho } \\
\text { (tipo chips) } \\
(\quad)\end{array}$ & $\begin{array}{l}\text { Bolacha } \\
\text { recheada } \\
(\quad)\end{array}$ & $\begin{array}{c}\text { Salada de frutas } \\
(\quad)\end{array}$ & $\begin{array}{l}\text { Barrinha } \\
\text { de cereal } \\
(\quad)\end{array}$ \\
\hline $\begin{array}{l}\text { Por que você prefere os } \\
\text { fast foods a produtos } \\
\text { saudáveis, como lanches } \\
\text { naturais? }\end{array}$ & $\begin{array}{l}\text { Custo elevado dos } \\
\text { produtos saudáveis } \\
(\quad)\end{array}$ & $\begin{array}{l}\text { Sabor (fast } \\
\text { foods são } \\
\text { mais } \\
\text { saborosos) } \\
(\quad)\end{array}$ & $\begin{array}{l}\text { Desconheciment } \\
\text { o das opções } \\
\text { saudáveis } \\
(\quad)\end{array}$ & $\begin{array}{l}\text { Praticidade } \\
(\quad)\end{array}$ \\
\hline $\begin{array}{l}\text { Algum membro da sua } \\
\text { família é obeso ou } \\
\text { diabético? }\end{array}$ & $\begin{array}{l}\text { Sim - obeso } \\
\left(\begin{array}{l})\end{array}\right.\end{array}$ & $\begin{array}{l}\text { Sim - } \\
\text { diabético } \\
(\quad)\end{array}$ & $\begin{array}{l}\text { Não } \\
(\quad)\end{array}$ & $\begin{array}{l}\text { Não sei } \\
(\quad)\end{array}$ \\
\hline
\end{tabular}

Fonte: Autoria própria (2018).

Ao término do preenchimento do questionário, foi indagado abertamente aos alunos se eles tinham o costume de ingerir muito açúcar diariamente e se eles sabiam claramente identificar a quantidade de açúcar presente nos alimentos. Após o questionamento, seguiu-se para a atividade 2 .

Figura 1 - Apresentação. Em A, preenchimento do questionário. Em B, dedução da quantidade de açúcar presente nos produtos disponibilizados. Em C, revelação da quantidade de açúcar. Em $\mathrm{D}$, uso dos modelos de célula, prato ideal e pirâmide alimentar para explicar a interação macro e microscópica dos componentes alimentares. Em E, uso de peneiras a fim de demonstrar a diferença entre os tipos de fibras. Em F, explicação dos termos presentes nos rótulos alimentícios. 


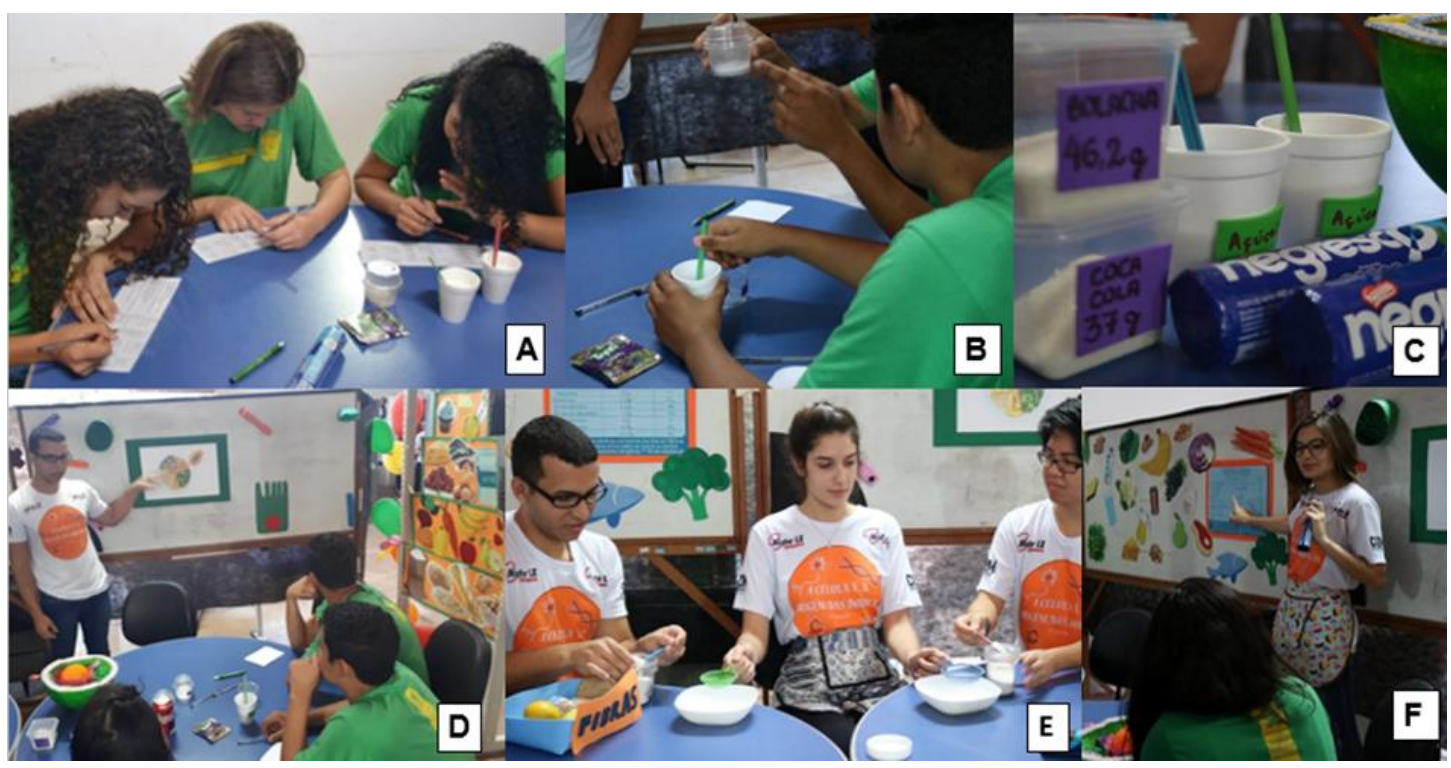

Fonte: Autoria própria (2018).

Atividade 2 - Foi realizado uma dinâmica na qual os alunos tentaram acertar a quantidade de açúcar presente em alguns alimentos como pacote de bolacha recheada, refrigerante e suco em pó (Figura 1-C). Para isso, foi disponibilizado um copo, uma colher, o açúcar e o alimento para ser manuseado. Nesse copo, os participantes colocavam a quantidade de açúcar que supunham estar presente no alimento. Em seguida, um dos acadêmicos revelava a real quantidade de açúcar presente no respectivo alimento.

A atividade 3 tratava-se do discernimento sobre alimentos light e diet. Explicou-se que no alimento light, alguns nutrientes ou o valor energético são reduzidos, mas eles ainda estão lá. Já no diet, a presença de alguns nutrientes como o açúcar, é insignificante ou ausente (SBD, 2014-2015b). Ressaltou-se, contudo, que o consumo deve ser moderado, pois essas qualificações não os tornam saudáveis.

$\mathrm{Na}$ atividade 4 foram abordados os componentes essenciais para a caracterização funcional e estruturas do organismo: proteínas, lipídios e carboidratos. Buscou-se demonstrar através de figuras e modelos didáticos a relação desses elementos essenciais com os alimentos contidos na pirâmide alimentar e o estrato de predominância. Além disso, demonstrou-se em qual local os componentes proteicos e lipídicos se encontram em um prato de comida balanceado, relacionando esses macronutrientes com sua importância para a constituição das células (Figura 1-D; Figura 2A). 
Durante a explicação sobre os lipídios, explanou-se que esse nutriente faz parte da composição de várias organelas e da membrana plasmática, todavia deveria ser consumido em doses moderadas devido a problemas associados ao ganho de peso. Após trazer os impasses do lipídio, deu-se ênfase à importância das fibras, ao citar os alimentos ricos - brócolis, verduras de folhas, alface e mamão - , sua composição química e principalmente suas funções: menor absorção de gordura, compor o bolo fecal, auxiliar os movimentos peristálticos e contribuir para lentidão no esvaziamento gástrico, aumentando a sensação de saciedade (FIB-2014). Para demonstrar isso, usou-se uma peneira que representava o estômago. Adicionava-se granola na peneira e em seguida, farinha - representando uma refeição de carboidratos acompanhada de fibras. Então, notava-se que a farinha descia mais devagar devido à presença da granola, aludindo à função de retardar o esvaziamento gástrico, um papel das fibras.

Acrescentou-se a essa atividade, a apresentação do equivalente da quantidade diária de fibras em gramas ( 25 a 40 gramas em média) por meio de alimentos contidos em uma cesta, os quais foram representados por 1 fatia de pão integral, 1 banana, 1 maçã, arroz e feijão, 1 laranja e 1 cenoura.

Em seguida, como mostrado na figura 1-E, foi realizado uma experiência para que o aluno compreendesse a absorção de carboidratos simples e complexos. Foi utilizado uma segunda peneira para representar o epitélio intestinal.

Depositou-se o açúcar refinado na peneira e um dos acadêmicos demonstrou que o açúcar passava rapidamente e sem qualquer interferência, analogamente ao carboidrato simples que é facilmente digerido e absorvido pelo intestino. Já a farinha integral sobre a peneira, passava devagar, semelhantemente à digestão e absorção dos carboidratos complexos. Essa dinâmica previa a compreensão de que carboidratos complexos possuem menor velocidade de absorção, o que implica em menor índice glicêmico comparado aos carboidratos simples.

Encerrada a etapa das fibras e absorção de carboidratos simples e complexos, passou-se para a etapa de compreensão sobre rótulos alimentícios (Figura 1-F). Nela foi usado um pacote de bolacha como exemplo de rótulo, o mesmo em que os alunos tentaram adivinhar a quantidade de açúcar presente. Primeiramente definiu-se o que seria 
considerado uma porção, ou seja, a quantidade que uma pessoa saudável deve ingerir de um determinado alimento. Além disso, definiu-se o que é valor energético - energia que esse alimento vai fornecer ao organismo. Após a explicação desses conceitos iniciou-se a leitura dinâmica do rótulo, relacionando as quantidades presentes no alimento com as quantidades indicadas de consumo de cada elemento pela OMS (OMS, 2003).

Figura 2-Em A, modelos de célula confeccionados pelos acadêmicos. Em B, varal com as placas "Mudar" e "Continuar".

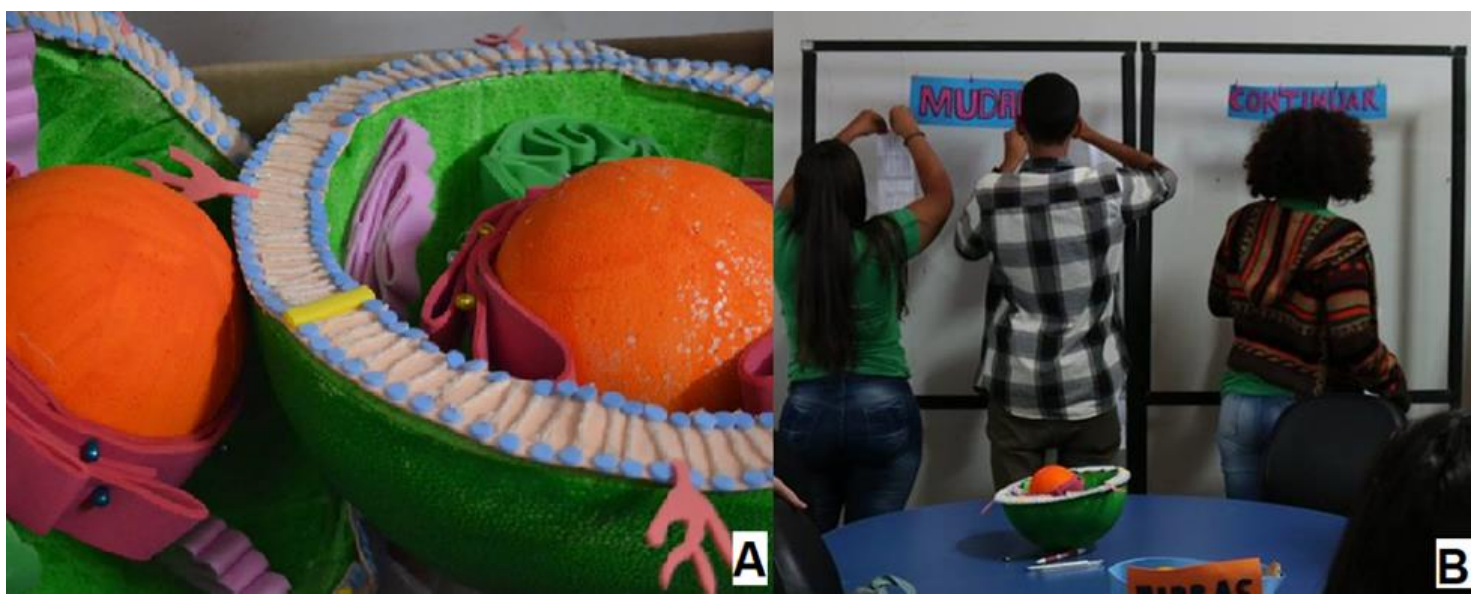

Fonte: Autoria própria (2018).

Por fim, os acadêmicos solicitaram aos estudantes participantes que analisassem as fichas que foram preenchidas no início das atividades da estação e que tentassem refletir sobre seus hábitos conforme a óptica adquirida na estação. Em seguida, os estudantes, para concretizarem a determinação da mudança ou permanência em relação aos hábitos alimentares próprios, escolhiam entre dois varais que continham as palavras: "Mudar" ou "Continuar" para anexar sua ficha (Figura 2-B). Foi feita uma breve discussão com os alunos e percebeu-se que a grande maioria estava dispostas a alterar seus hábitos. Após a atividade, os alunos puderam levar suas fichas avaliativas para casa.

\section{RESULTADOS E DISCUSSÃO}

A base do presente trabalho foi a dinâmica de conscientização de alunos do ensino médio sobre os macronutrientes e sua importância para a homeostasia celular. Nessa dinâmica, os alunos foram estimulados a refletir sobre seus hábitos alimentares e muitos relataram a ingestão de refrigerantes diariamente. Em trabalho de Lopes et al. (2010), que 
analisou os fatores de risco associados à obesidade e ao sobrepeso em crianças em idade escolar matriculadas no ensino fundamental I de uma escola pública de São Paulo, a porcentagem dos estudantes eutróficos que consumiam refrigerantes todos os dias era de $11,2 \%$. O debate sobre o consumo de açúcar, mediante uma reflexão individual respaldada por um questionário distribuído, foi uma forma importante de estimular o aluno a acessar a informação de que esse tipo de alimento pode provocar doenças como a obesidade.

Em adição a essa discussão, foi trabalhado a importância de se estudar o alimento que consumimos por meio da leitura dos rótulos alimentares. Segundo o manual Rotulagem Nutricional Obrigatória: manual de orientação aos consumidores (ANVISA, 2005), aproximadamente $70 \%$ das pessoas que consultam o serviço Disque-Saúde do Ministério da Saúde consultam os rótulos dos alimentos no momento da compra. Contudo, de acordo com a discussão junto aos escolares, pouquíssimos deles já haviam lido um rótulo de algum tipo de alimento, o que implica no baixo conhecimento sobre a composição dos alimentos industrializados que ingerem diariamente.

Ainda com base no comportamento dos estudantes, a maioria demonstrou preferência por alimentos industrializados, como os fast foods. Um exemplo disso, foi que mais da metade deles levantaram as mãos quando perguntado se consomem esse tipo de alimento devido ao seu sabor, e apenas uma pequena parte disse que os consumiam pela falta de conhecimento sobre alimentação saudável.

Ainda que o consumo de verduras e legumes no estado de Mato Grosso do Sul seja maior que a média brasileira (SISVAN, 2018), a maioria dos alunos que participaram consideraram seus hábitos alimentares como não saudáveis, informação obtida pela equipe quando solicitado para eles levantarem as mãos. Contudo esses mesmos alunos demonstraram vontade de mudá-los mediante as atividades propostas pela Estação Cozinha e Saúde. Isso pode ser verificado na atividade de encerramento da estação, a dinâmica do varal, em que os alunos optaram por, simbolicamente, pendurar suas fichas em dois varais que continham os verbos "Mudar" ou "Continuar" para demonstrar sua intenção e percepção quanto aos seus hábitos alimentares. 
Atividades semelhantes a dinâmica do açúcar já existem e são muito aplicadas em vários projetos, como o Trabalho de Educação Nutricional da Faculdade União das Américas (UniAmérica) de Foz do Iguaçu, PR (SCHONS et al, 2016). Porém, esse trabalho diferencia-se da maioria na medida em que tornam os alunos protagonistas na construção do próprio conhecimento, pois eles que deduziram as quantidades de açúcar, bem como responderam às perguntas feitas durante as explicações e apontavam as organelas no modelo de célula usada na atividade (Figura 2-A). A atividade de quantificação do açúcar permitiu, por sua vez, à equipe uma clara visão da falta de informação e conhecimento dos alunos quanto a esse assunto, uma vez que eles colocavam menos do que o informado na embalagem. Foi notório, portanto, a surpresa dos participantes ao se depararem com tamanha proporção da quantidade de açúcar.

\section{CONCLUSÃO}

A realização do projeto proporcionou a interação e a troca de conhecimento entre os extensionistas e os alunos do ensino médio que compareceram ao evento. Aos acadêmicos, a atuação no projeto mostrou-se bastante gratificante, devido à possibilidade de compartilhar informações relevantes, de maneira dinâmica e interativa com os alunos do ensino médio. A descoberta dos alunos sobre a quantidade de açúcar presente em alimentos diariamente fez despertar nos adolescentes o desejo de mudança de hábitos. Conclui-se, assim, que a prevenção a doenças crônicas comuns pode ser inspirada por ações como essas, as quais tornam palavras e números mais concretos e podem estimular desde cedo os jovens a se tornarem indivíduos mais conscientes de sua alimentação.

\section{AGRADECIMENTOS}

À Casa da Ciência e Cultura, à Escola Estadual Orcírio Thiago de Oliveira, aos patrocinadores Curso de biologia professora Juliene Cândida, Danilo Bachega Eventos, DZM Eventos, Mister LX Camiseteria, Professora Milena - Biologia, Santa Rita Decor, e aos demais integrantes idealizadores das estações do projeto, Alyssa Maria Fernandes Shimizu, Bruna de Andrade Mittelstaedt, Carlos Alberto Bento Júnior, Fábio Henrique Sobrinho Pael, Flávia Nezi, Gustavo Tsuyoshi Senra Masuko, Larissa Taemy Kayano, 
Leonardo Rosolen Iunes, Lívia de Arruda Pedrini, Mariana Barreira Bertoluci, Matheus Maresciallo Matins Zandonadi, Natália Ogeda Portilho, Pedro Luiz da Costa Silva,

Philippe Villas Boas Duarte, Raíssa de Andrade Águas, Thalitta Mendes Cavalcante, Thamiris Melo de Oliveira, Willy Abdo Ashd e Yasmin Rodrigues Portela.

\section{REFERENCIAS}

AMORIM, A. S. A influência do uso de jogos e modelos didáticos no ensino de Biologia para alunos de Ensino Médio. 2013. 50p. Monografia (curso de licenciatura em Ciências Biológicas) - Universidade Estadual do Ceará - UAB\UECE, Beberibe, 2013. Disponível em: <http://www.uece.br/sate/dmdocuments/bio_beberibe_amorim.pdf $>$ Acesso em: 25 de jan. 2018.

ANVISA. Estudo aponta grande quantidade de sódio em alimentos industrializados. ASCOM, 2010. Disponível em: http://portal.anvisa.gov.br/noticias//asset_publisher/FXrpx9qY7FbU/content/estudo-aponta-grande-quantidade-de-sodioem-alimentos-industrializados/219201/pop_up?inheritRedirect=false Acesso em: 21 de dez. 2018.

ANVISA. Rotulagem nutricional obrigatória: manual de orientação aos consumidores. Ministério da Saúde, Agência Nacional de Vigilância Sanitária / Universidade de Brasília, 2005.Disponível em: https://bit.ly/3fmzKe1. Acesso em: 23 de out. 2018.

ARAÚJO, M.S. LÚDICO: aprender de forma prazerosa. Cadernos de Pesquisa. v. 19, n. 3, p.71-78, 2012.

BRASIL. Em Mato Grosso do Sul, $50 \%$ dos adolescentes acompanhados no SUS consomem produtos industrializados. Ministério da Saúde, 2018. Disponível em: <http://portalms.saude.gov.br/noticias/agencia-saude/44536-em-mato-grosso-do- 
$\underline{\text { sul-50-dos-adolescentes-acompanhados-no-sus-consomem-produtos-industrializados> }}$

Acesso em: 20 de out. 2018.

BRASIL. Lei ${ }^{\circ}$ 9.394, de 20 de dezembro de 1996. Estabelece as diretrizes e bases da educação nacional. Diário Oficial da União, Brasília, 23 de dezembro de 1996. Disponível em: http://www.planalto.gov.br/ccivil_03/leis/L9394.htm. Acesso em: 18 de dez 2018. 2017.

FACCIONI, L.C; SOLER, R.R. Abordagem lúdica sobre os aspectos celulares do diabetes e da obesidade para alunos do ensino médio. Revista Brasileira de Extensão

Univversitária v.9, n.1. P. 27- 37, jan.-abr 2018.

FIB - FOOD INGREDIENTS BRASIL. Dossiê Fibras Revista-Fi, nº 30 - 2014. Disponível em: https://revistafi.com.br/upload_arquivos/201606/2016060405772001464892824.pdf. Acesso em: 20 de out. 2018.

KLAUBERG, S. D. W. O Lúdico no Ensino da Biologia - Uso de um modelo didático para ensino da divisão celular mitótica. $201521 \mathrm{f}$. Monografia (Especialização em Genética para Professores do Ensino Médio)-Universidade Federal do Paraná, Nova Londrina, 2015.

LOPES, P.C.S.; PRADO, S.R.L.A.; COLOMBO, P. Fatores de risco associados à obesidade e sobrepeso em crianças em idade escolar. Revista Brasileira de Enfermagem, Brasília , v. 63, n. 1, p. 73-78, fev. 2010. Disponível em: <http://www.scielo.br/scielo.php?script=sci_arttext\&pid=S0034$\underline{71672010000100012 \& \operatorname{lng}=\mathrm{en} \& \mathrm{nrm}=\mathrm{iso}}>$ Acesso em: 23 de out. 2018.

OBLINGER, D.G. Multimedia in the classroom. Information Technology and Libraries, v. 12, n. 2, p. 246-247, 1993. 
OMS: FAO 32. (2003) Relatório Pericial sobre dieta alimentar, nutrição e prevenção de doenças crônicas. Organização Mundial da Saúde. Disponível em: < https://www.who.int/nutrition/publications/pressrelease32_pt.pdf> Acesso em: 26 maio.

2019.

OPAS - ORGANIZAÇÃO PAN-AMERICANA DA SAÚDE (2017). Obesidade entre crianças e adolescentes aumentou dez vezes em quatro décadas, revela novo estudo do Imperial College London e da OMS. Disponível em: 〈https://bit.ly/31jgs4h〉 Acesso em: 21 de dez. 2018.

ORLANDO, T.C. et al. Planejamento, montagem e aplicação de modelos didáticos para abordagem de Biologia celular e Molecular no Ensino Médio por graduandos de Ciências Biológicas. Revista Brasileira de Ensino de Bioquímica e Biologia Molecular, v. 10, p. 1-17, 2009.

RODRIGUES, E.M.; BOOG, M.C. FABER. Problematização como estratégia de educação nutricional com adolescentes obesos. Caderno de Saúde Pública, Rio de Janeiro, v. 22, n. 5, p. 923-931, mai 2006. Disponível em: $\langle$ http://www.scielo.br/scielo.php?script=sci_arttext\&pid=S0102311X2006000500005\&lng=en\&nrm=iso $>$ Acesso em: 18 de dez. 2018.

SCHONS, L. et al. Trabalho de Educação Nutricional - Dinâmica o açúcar por trás dos alimentos, 2016. Disponível em: <http://uniamerica.br/wpcontent/uploads/2016/07/Projeto-Nutri\%C3\%A7\%C3\%A3o-OA\%C3\%A7\%C3\%BAcar-por-tr\%C3\%A1s-dos-alimentos.pdf> Acesso em: $21 \mathrm{de} \mathrm{dez.}$ 2018.

SBD. SOCIEDADE BRASILEIRA DE DIABETES. Diabetes mellitus tipo 2 no jovem. Diretrizes SBD, 2014-2015a. 
SBD. SOCIEDADE BRASILEIRA DE DIABETES. Princípios para a orientação nutricional no Diabetes Mellitus. Diretrizes SBD, 2014-2015b.

SISVAN. Sistema de Vigilância Alimentar e Nutricional. Relatórios de Acesso

Público, 2018 Disponível em: < http://sisaps.saude.gov.br/sisvan/relatoriopublico/index> Acesso em: 21 de dez. 2018.

THIOLLENT, M. Metodologia da pesquisa-ação. São Paulo: Cortez, 1994.

Recebido em: 14 de agosto de 2019.

Aceito em: 14 de maio de 2020. 